\title{
Treating Insomnia in Older Adult Patients: Limiting Benzodiazepine Use
}

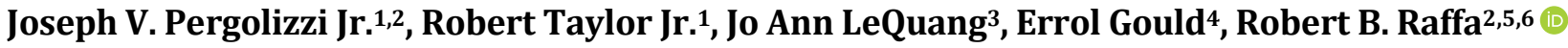

${ }^{1}$ NEMA Research Inc., Naples, FL, USA

${ }^{2}$ Neumentum, Palo Alto, CA, USA

${ }^{3}$ LeQ Medical, Angleton, TX, USA

${ }^{4}$ Pernix Therapeutics, Morristown, NJ, USA

${ }^{5}$ University of Arizona College of Pharmacy, Tucson, AZ, USA

${ }^{6}$ Temple University School of Pharmacy, Philadelphia, PA, USA

Email: robert.raffa@gmail.com

How to cite this paper: Pergolizzi Jr., J.V., Taylor Jr., R., LeQuang, J.A., Gould, E. and Raffa, R.B. (2019) Treating Insomnia in Older Adult Patients: Limiting Benzodiazepine Use. Pharmacology \& Pharmacy, 10, 116-129.

https://doi.org/10.4236/pp.2019.103010

Received: December 20, 2018

Accepted: March 18, 2019

Published: March 21, 2019

Copyright $\odot 2019$ by author(s) and Scientific Research Publishing Inc. This work is licensed under the Creative Commons Attribution International License (CC BY 4.0).

http://creativecommons.org/licenses/by/4.0/

\begin{abstract}
As aging comes, an increased prevalence of medical maladies and chronic pain independently or interactively disrupt sleep, which in turn can exacerbate either one. Furthermore, anxiety about pain can further negatively impact sleep. Fortunately, good quality sleep can improve pain management. Because benzodiazepine receptor agonists (including the " $\mathrm{Z}$ " drugs) can reduce anxiety and improve sleep, they seem a convenient choice. However, their use in this population, particularly for more than short-term (guidelines range from 2 to 6 weeks $\max$ ), is not recommended because of increased likelihood of falls, further disruption of sleep, dependence, and problems with discontinuation (withdrawal). Besides, this population is often likely to take concomitant medication for pain or other central nervous system depressants leading to potentially serious and even life-threatening interactions involving synergistic amplification of respiratory depression (opioids being a particularly dangerous interaction). Therefore, insomnia in older adults should ideally be treated with a non-benzodiazepine receptor agonist; if indicated, they may be used, but should be closely monitored and tapered to avoid long-term adverse problems (direct or from withdrawal). Older adult patients with insomnia may be more optimally treated with sleep aids that do not interact with the $\mathrm{GABA}_{\mathrm{A}}$ receptor.
\end{abstract}

\section{Keywords}

Pain, Insomnia, Older Adults, Benzodiazepines, “Z”-Drugs, GABA $A_{A}$ Receptor

\section{Introduction}

Chronic pain becomes increasingly prevalent with increasing age, and problems 
of insomnia occur more frequently with aging and in the chronic pain population [1]. In a study of 2790 older adults with chronic pain, the rate of clinical insomnia was $24.6 \%$, and these patients were more likely to experience more frequent episodes of pain and pain of greater intensity than age-matched chronic pain patients without insomnia [2]. The treatment of insomnia in the older chronic pain population remains problematic because many of these patients are on (usually necessary) polypharmacy, and the introduction of other medications increases the risk of potential pharmacokinetic drug-drug interactions. Furthermore, many traditional sleep aids are associated with compliance-limiting adverse events or are not indicated for long-term use. A better agent for improving sleep in the geriatric chronic pain population would be an agent that would improve sleep latency (onset time), prolong the duration of sleep, prevent middle-of-the-night wakefulness, have few and tolerable adverse events, not be associated with increased somnolence or daytime drowsiness, and not have abuse potential or problems associated with discontinuation (withdrawal) [3].

Sedative drugs (e.g., benzodiazepines, barbiturates, and certain other sleep aids) are widely used for treating insomnia, although the Beers Criteria states that benzodiazepines, non-benzodiazepine receptor agonists (the so-called "Z"-drugs), and other sedative-hypnotics are not appropriate for older patients [4]. In one survey, $8.7 \%$ of individuals between the ages of 65 and 80 in the United States had a prescription for a benzodiazepine, and of this group nearly a $1 / 3^{\text {rd }}$ were using them long-term, which the survey defined as $>120$ days (but it should be noted that current guidelines recommend from 2 to 6 weeks max) [5]. Women received benzodiazepine prescriptions more often than did men and $10 \%$ of all females $65-80 \mathrm{yr}$ had been prescribed a benzodiazepine [5]. Overall, about $1 / 4^{\text {th }}$ of benzodiazepine prescriptions are for long-acting formulations [5]. Most benzodiazepine prescriptions are written by non-psychiatrics; in the population of adults between 18 and 80 , about $2 / 3^{\text {rds }}$ of prescriptions are written by non-psychiatrists and in the subgroup of individuals between the ages $65-80$, $90 \%$ of prescriptions for benzodiazepines are written by non-psychiatrists [5].

Despite growing evidence of risks associated with benzodiazepines in older patients, a retrospective study based on data from the National Ambulatory Medical Care Survey of primary care providers $(\mathrm{n}=14,282)$ and psychiatrists ( $\mathrm{n}$ $=1095$ ) found a significant increase over the years in the rate of visits for benzodiazepines (from $5.6 \%$ in 2003-2005 to $8.7 \%$, adjusted odds ratio $1.62, p<0.001$ ), with increases noted among those with pain diagnoses [6].

Benzodiazepines are increasingly prescribed to geriatric pain patients in the United States and other parts of the world, institutionalized individuals and community dwelling-outpatients, despite well-established evidence that they are associated with high risks [7]. The aim of this study was to present a concise summary of the basic science behind benzodiazepine pharmacology, the associated risks of benzodiazepine use in the older adults and the beneficial role of sleep in chronic pain patients, and finally to consider possible alternative treatment options. 


\section{Methods}

This narrative review is based on literature searches in PubMed, MedLine, and other on-line sources (1946-2019) for "benzodiazepine $\times$ geriatric $\times$ pain" (31 results), "benzodiazepine $\times$ geriatric $\times$ sleep" (112 results with 15 results from the past 5 years) and "benzodiazepine geriatric" (595 results, 148 in the past 5 years). In addition, the authors searched for related terms and reviewed the bibliographies of key articles.

\section{Benzodiazepine Pharmacology}

Benzodiazepines are chemically distinct from the so-called "Z-drugs" (e.g., Zaleplon, Zolpidem and Zopiclone), but since they have similar pharmacology, they will be considered here together. The benzodiazepines are composed of a benzene ring plus a diazepine ring and act at the benzodiazepine receptor (BZD-R); the " $Z$ "-drugs lack the distinctive BZD chemical structure (Figure 1), but likewise act as agonists at the BZD-R.

Gamma $(\gamma)$-aminobutyric acid (GABA) is a neurotransmitter that mediates inhibitory transmissions at most brain neurons. Three GABA-receptor $\left(G_{A B A}-R\right)$ types have been identified, which are designated by subscripts A (ionotropic), $\mathrm{B}$ (metabotropic), and $\mathrm{C}$ (not relevant to this discussion) [8]. There are multiple subtypes of $\mathrm{GABA}_{\mathrm{A}}$ receptors [8]. $\mathrm{GABA}_{\mathrm{A}}-\mathrm{R}$ is an ionotropic type receptor, which means that it is a ligand-gated ion channel. Activation by an endogenous agonist (i.e., GABA), exogenous agonist, or positive allosteric modulator (e.g., benzodiazepines or " $\mathrm{Z}$ "-drugs) results in an increase in $\mathrm{Ca}^{2+}$ efflux as the mechanism of signal transduction. Most $\mathrm{GABA}_{\mathrm{A}}$ receptors consist of five subunits (designated $\alpha, \beta$, and $\gamma$ ) [8]. There are at least six different $\alpha$-subunits, four different $\beta$-subunits, and three different $\gamma$-subunits. Thus, there are a large number of possible subunit combinations, resulting in $\mathrm{GABA}_{\mathrm{A}}$ receptors with different and distinct electrophysiological and pharmacological characteristics. Benzodiazepine receptors are allosteric modulatory sites located on the $\mathrm{GABA}_{\mathrm{A}}$ receptor complex [9].

Benzodiazepines and other similar agents act at the brain's BZD-Rs by potentiating the inhibitory effects of GABA in the brain. [10] [11] [12]. Other drugs may also act at these binding sites as agonists (such as midazolam and other

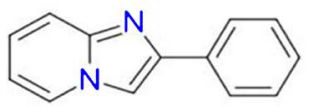

Imidazopyridines

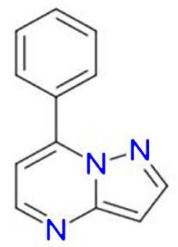

Pyrazolopyrimidines<smiles>O=C1c2nccnc2C(O)N1c1ccccn1</smiles>

Cyclopyrrolones<smiles>[R]C1=CCN=C(c2ccccc2[R2])c2cc([R])ccc21</smiles>

Benzodiazepines

Figure 1. Structural template of BZDs and some non-BZD BZD-R agonists: imidazopyridines (e.g., zolpidem), pyrazolopyrimidines (e.g., zaleplon), and cyclopyrrolones (e.g., eszopiclone). 
benzodiazepines), as partial agonists (such as bretazenil), antagonists (such as flumazenil), partial inverse agonists, and even as inverse agonists [8]. About 35 benzodiazepine derivatives are available as drugs [13]. Depending on the compounds, GABAergic transmission may be enhanced, reduced, or not affected by the binding activity [9]. The brain contains high-affinity binding sites for benzodiazepine agents, which bind to these sites in a way that is stereospecific and saturable (Figure 2) [9].

Although the presence of these receptors is widespread in the human brain, the highest density of BZD-R is found in cortical and limbic regions (such as hippocampus, nucleus accumbens, amygdala, and mammillary bodies). Basal ganglia, thalamic and hypothalamic nuclei have intermediate densities, with lower density presence in brain stem and white matter [14]. The central BZD-R was discovered and described in the literature in 1977 [15] [16], was demonstrated on radiography in humans in 1988 [14], and can be summarized as receptors that exert a positive allosteric modulation of $\mathrm{GABA}_{\mathrm{A}}$ receptors.

Peripheral BZD-R was discovered around 1992 [17]. These sites might better be known as translocator proteins (TSPO), the function of which has not yet been fully elucidated. However, TSPO may be involved in steroid biochemistry, cell proliferation, apoptosis, and immunomodulatory effects. TSPO-null mice $\left(\mathrm{TSPO}^{--}\right)$are viable [18]. As demonstrated in a study of six healthy subjects undergoing positron emission tomography (PET) scans, TSPO sites are widespread throughout the body, and are associated with mitochondria (the cell's energy organelles) and immune cells [19].

Benzodiazepines are highly protein-bound and well absorbed in the body. Some, such as lorazepam, have a hydroxyl group and are metabolized via glucuronide conjugation with relatively short elimination half-life [13]. Others are demethylated or oxidized prior to conjugation, resulting in a longer half-life and the potential for more accumulation over time. Some benzodiazepines have
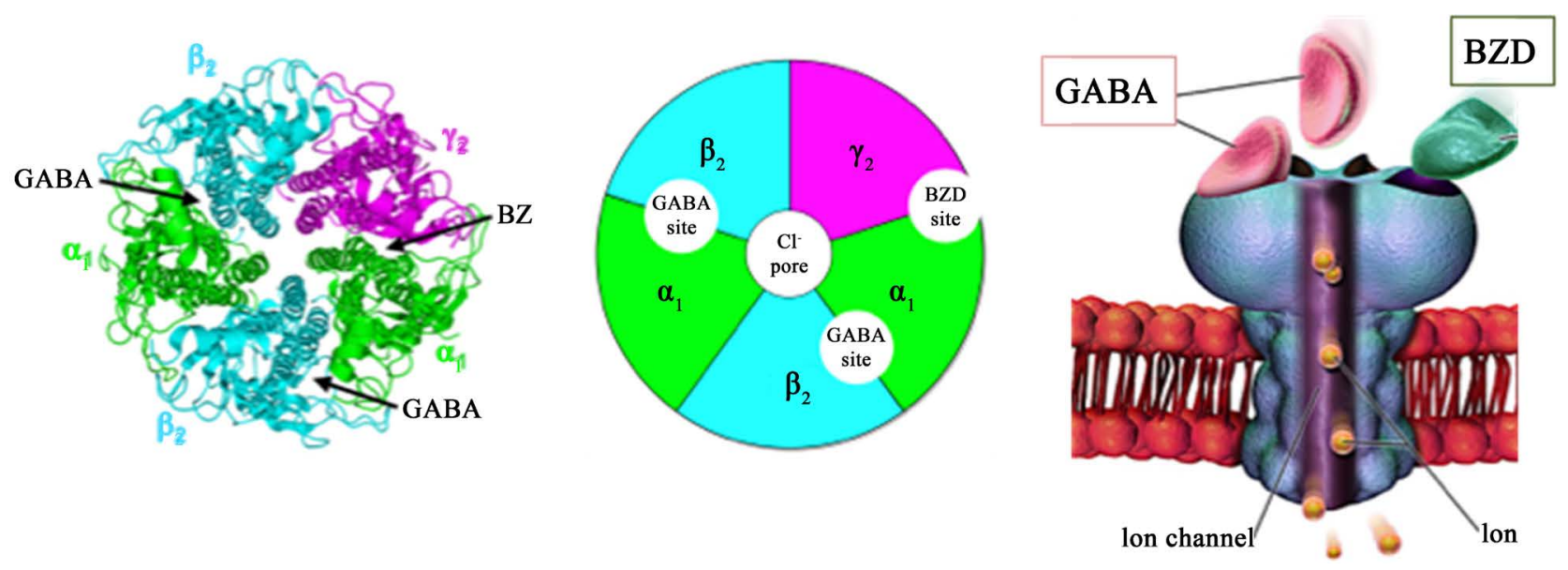

Figure 2. The $\mathrm{GABA}_{\mathrm{A}}$ receptor and benzodiazepine binding site. From https://commons.wikimedia.org/wiki/File:NAchR_2BG9.png, https://commons.wikimedia.org/wiki/File:GABAA-receptor-pro-tein-example.png, and https://com;mons.wikimedia.org/wiki/File:Cell_GABA_Receptor.png. 
metabolites known to be pharmacologically active (some are even considered pro-drugs) [13]. For clinical classification purposes benzodiazepines are sometimes grouped according to their clinical properties, that is, into anxiolytics and hypnotics, although these distinctions are not always clear cut in that there is overlap [13].

Benzodiazepines bind to specific sites on $\mathrm{GABA}_{\mathrm{A}}$ receptor complexes in the brain, increasing the flow of chloride and making neurons hyperpolarized (less excitable). Because benzodiazepines in general have a rapid onset of action they work well for falling asleep, but if their half-lives are short patients may awaken in the middle of the night or earlier than they wish. Unfortunately, longer-acting benzodiazepines may be associated with adverse events such as sleep-related behaviors that carry over the next day [20].

\section{Risks of Benzodiazepine Use in Older Adult Pain Patients}

Side effects of benzodiazepines include drowsiness, fatigue, lethargy, sedation, stupor, disturbed concentration, disturbed attention, hypotonia, ataxia, "hangover" effects, and the recurrence of symptoms upon drug discontinuation ("symptom rebound"), and the panoply of new symptoms that might be introduced by dependence or withdrawal symptoms [21] [22] [23] [24]. Benzodiazepines have also been associated with increased risk for falls and bone fractures, and traffic accidents [25] [26] [27]. Benzodiazepines are contraindicated in patients who have myasthenia gravis, ataxia, sleep apnea, chronic respiratory insufficiency, spinal or cerebellar ataxia, angle-closure glaucoma, or acute intoxication with a central nervous system-depressant. Particular caution is warranted in prescribing these drugs to patients older than 65 yr because of adverse psychomotor effects and cognitive symptoms (such as memory loss, attention deficits, problems with concentration, etc.) [23] [28] [29]. Specifically, benzodiazepines are not appropriate to treat insomnia in the elderly or, if absolutely necessary, used only for a short period of time ( $\leq 6$ weeks) under close clinical supervision [30].

In 2016, the U.S. Food and Drug Administration (FDA) issued a communication about the serious and potentially life-threatening risks of combining benzodiazepines with the opioids [31]. These and other drugs (e.g., alcohol, barbiturates, and propofol) may create additive or supra-additive levels of central nervous system depression when used concomitantly with benzodiazepines.

Morbidity associated with benzodiazepine use appears to be more severe among geriatric patients. In a two-year retrospective study of 387 consecutive patients admitted to hospital for benzodiazepine poisoning (unintentional or intentional overdose), hospital length of stay was longer in those $>65$ years compared to younger patients ( 15 - $65 \mathrm{yr}$ ). The incidences of coma, respiratory failure, and aspiration pneumonia occur more often in older patients [32], and chronic use of benzodiazepines is associated with diminished quality of life (limitations in mobility, instrumental activities of daily living, and social participa- 
tion) [33].

\section{Neurotransmitters in the Sleep/Wake Cycle}

The human sleep/wake cycle is governed by the "flip-flop" of homeostatic and circadian systems, which compete against each other. The homeostatic system regulates the amount of sleep, and it generally ramps up the longer one that is wakeful. The physiological circadian "internal clock" relies on internal and external cues (mainly light and dark) to govern the timing of sleep [34]. Thus these two systems work in coordinated fashion with each other, switching back and forth. It is not a binary system, but rather a progressive gradation between wakefulness and sleepiness in varying degree [35].

GABA is the major inhibitory neurotransmitter in the brain and in inhibitory circuits. It is the main neurotransmitter in the ventrolateral preoptic nucleus (VLPO), which promotes sleep. During sleep, the VLPO inhibits histamine (histamine promotes wakefulness). The wakeful system is mediated in part by histamines in tuberomammillary nucleus, serotonin from the raphe nuclei, orexin from the perifornical area, dopamine from ventral periadqueductal gray area, and others [35]. Of particular note is orexin, a peptide produced in hypothalamus that projects to some of the same targets that GABA inhibits [36]. Orexin decreases sleep-promoting activity and thus indirectly promotes wakefulness [37]. The exact role of orexin in sleep-wakefulness is still being elucidated. But it is known, for example, that $90 \%$ of narcoleptics have inadequate levels of orexin [38].

While a great deal remains to be learned about the neurotransmitters associated with the sleep-wake cycle, GABA appears to regulate the homeostatic side and orexin circadian cycles. Some evidence suggests that insomniacs have lower levels of GABA [39]. This, in turn, implies that medications that increase GABA may be helpful in treating insomnia. In a study of animals and humans, blocking orexin receptors encouraged sleep [40]. Therefore, both systems may be potential targets for insomnia drugs.

\section{Alternative Therapies for Insomnia in Older Adult Pain Patients}

Chronic pain and insomnia often occur together in aging, sometimes in a self-regenerating vicious cycle. Benzodiazepines are widely used for the treatment of insomnia. Unfortunately, about a quarter of those taking benzodiazepines are taking them long term, where the risks of direct adverse effects, or withdrawal, are not well known by many prescribers [41]. For older adults with chronic insomnia, nonpharmacological methods (such as cognitive behavioral therapy and sleep hygiene strategies) should be considered as $1^{\text {st }}$-line approaches, with pharmacotherapy reserved for more severe cases [42]. Nonpharmacological approaches are particularly relevant to older individuals who may have age-related changes in drug metabolism, organ function, or central nervous sys- 
tem functioning. Furthermore, older individuals suffering with chronic pain syndromes likely are on (legitimate) polypharmacy, making it beneficial to consider reducing the addition of new drugs to the current pharmacological regimens. In older patients who suffer with chronic pain, there is a particular risk of concomitant prescribing of opioid analgesics with benzodiazepines-a combination about which new CDC opioid prescribing guidelines warn [43]. The Food and Drug Administration (FDA) requires labeling warnings about the combined use of benzodiazepines and opioids in labeling [31].

While numerous pharmacological approaches are available to treat chronic insomnia, studies of the drugs for long-term use in the older adult chronic pain population are rare [42]. A PubMed search of the keyword phrase "insomnia medication $\times$ chronic pain $\times$ geriatric" produced three results, none of which were clinical trials.

The American Geriatrics Society Beers Criteria advises against the use of benzodiazepine and non-benzodiazepine BZD-R agonists in older adults (they have an increased sensitivity and decreased metabolism for long-acting agents), stating that all BZD-R agonists increase in geriatric patients the risks for cognitive impairment, delirium, falls, fractures, and motor vehicle crashes [44]. Thus, alternative insomnia medications must be considered, particularly those that do not interact with $\mathrm{GABA}_{\mathrm{A}}$.

For treating insomnia, clinicians should first consider the possibility of organic disorders that may necessitate specific treatment, such as narcolepsy or sleep apnea [45]. Prior to initiating a treatment, clinicians should obtain a complete medical and psychiatric history, including indication of mental health problems, dementia, or substance abuse, and address them. Clinicians should also review the pharmacological regimen of the patient and adjust, if possible, any agents (prescription or OTC) the patient is taking that many interfere with proper sleep. As $1^{\text {st }}$-line treatment, clinicians might want to consider behavioral or cognitive therapy rather than drugs. These are not part of the present review, but may include sleep restrictions, stimulus control, and changes in patient's dysfunctional beliefs. Usually, pharmacotherapy should be reserved for those who do not respond to nonpharmacological treatments. As much as possible, chronic use of such medication should be avoided, but a short course might be appropriate [46]. New drugs for treating insomnia that do not target the $\mathrm{GABA}_{\mathrm{A}}-\mathrm{R}$ system are emerging [47]-[56].

For patients with chronic neuropathic pain or for those whose insomnia may be related to restless leg syndrome, pregabalin or gabapentin might be appropriate. Valerian and melatonin are not well studied and may be considered as supplements [3]. Many drugs are used off-label to treat insomnia in elderly chronic pain patients. The American Academy of Sleep Medicine recommends that off-label drugs be considered only when the patient fails to respond to approved drugs or when that patient has a comorbid indication for which the drug is appropriately prescribed and the drug happens to benefit the patient as a sleep aid 


\section{[57].}

\section{Discontinuance and Withdrawal}

With continued administration, almost all drugs elicit a progressive increasingly large compensatory response that works in opposition to the direct drug-induced effect [58]. The observable external manifestation of this physiologic adjustment is a progressive decrease in drug-induced effect with each subsequent administration of dose, a process termed development of tolerance [59]. It should be noted that "tolerance" as used here is a basic science term and it is not the same as the lay term meaning "getting used to" something. The development of tolerance occurs at different rates and to different extents for different drugs. Perhaps the most well-known example of the development of tolerance is the development of tolerance to opioid drugs (morphine, oxycodone, etc.). In the clinical setting, this means that more opioid drug is needed to provide the same level of pain relief. In the case of opioid substance abuse, this means that an ever-increasing amount of drug is required to achieve the same level of desired effect. Because the process of requiring more drugs is similar in both cases, they are sometimes conflated to erroneously suggest that development of tolerance to a drug is the same as abuse or "addiction". However, they are not the same, and are demonstrably separable [60].

The development of tolerance to benzodiazepines should not generally be a concern for the typical patient for whom the benzodiazepines are prescribed properly per the product labeling-viz., for "short-term" [61]. However, benzodiazepines are often prescribed for durations that far exceed instructions in FDA product labeling [62]. While not necessarily a problem per se, the development of tolerance is manifested in an important, and often negative, manner upon abrupt cessation of drug use. In this situation, the compensatory physiological mechanisms are now unopposed, and the person (legitimate user or abuser) experiences symptoms opposite to the drug-induced effects. These effects are termed "withdrawal symptoms", and the process itself is termed "withdrawal". [63] Unlike the development of tolerance, withdrawal symptoms are immediately noticeable to the person, are disagreeable or dysphoric, and they serve as a drive to want to restore physiological homeostasis by taking the drug again, which contributes to the phenomenon that is known as "craving" [64]. The important point to note is that the desire to take the drug is not related to the initial medical need, but rather to a desire to counteract the unpleasant experiences of not taking it.

The difficulties associated with withdrawal and craving can be avoided or ameliorated in several ways. One is to reduce the development of tolerance by limiting benzodiazepine prescribing to the recommended use "short-term" per current guidelines. Another is to avoid abrupt discontinuation of drug by "tapering" at the end of the course of treatment. Detailed advice about effective tapering of benzodiazepines is readily available [65]. 
When benzodiazepines are administered for the right reasons, at the right dose, and for the right duration (short-term only), they are important, effective and safe medications. And if tapered at the end of therapy, withdrawal is often mild or even uneventful. Unfortunately, in some instances-usually with excessive use, but sometimes with normal use-and for some patients, withdrawal can be prolonged and present a medical puzzle. The symptoms can be diverse, chronic, variable, and patient-specific. This makes diagnosis, let alone treatment, extremely difficult for time-constrained healthcare providers. Worse still, it is a generally under-recognized problem by patients, their families, healthcare providers, insurers, and regulatory agencies [62].

\section{Conclusion}

Insomnia is a prevalent condition in the older adult pain population. As a result of the lack of adequate quantity and quality of sleep, a vicious cycle is initiated with consequential further decrease in quality of life. But treating insomnia in geriatric chronic pain patients is not straightforward, and it requires clinical prudence. Short-term use of benzodiazepines and the " $Z$ "-drugs, which may be a reasonable option for some younger adult patients, is not generally recommended for use in older adults, and is specific cautioned against by the CDC for patients on opioid therapy. This population requires extra thoughtful clinical judgment and thorough and persistent follow-up. The $1^{\text {st }}$-line approach in this population involves nonpharmacologic treatment strategies followed if needed by newer drugs that do not directly affect the $\mathrm{GABA}_{\mathrm{A}}$ system.

\section{Conflicts of Interest}

The authors declare no conflicts of interest regarding the publication of this paper.

\section{References}

[1] Roberts, M. and Drummond, P. (2016) Sleep Problems are Associated with Chronic Pain over and above Mutual Associations with Depression and Catastrophizing. The Clinical Journal of Pain, 32, 792-799.

https://journals.lww.com/clinicalpain/pages/articleviewer.aspx? $?$ year $=2016 \&$ issue $=0$ 9000\&article $=00007 \&$ type $=$ abstract https://doi.org/10.1097/AJP.0000000000000329

[2] Dragioti, E., Bernfort, L., Larsson, B., Gerdle, B. and Levin, L.A. (2018) Association of Insomnia Severity with Well-Being, Quality of Life and Health Care Costs: A Cross-Sectional Study in Older Adults with Chronic Pain (PainS65+). European Journal of Pain, 22, 414-425.

https://onlinelibrary.wiley.com/doi/abs/10.1002/ejp.1130 https://doi.org/10.1002/ejp.1130

[3] Schroeck, J.L., et al. (2016) Review of Safety and Efficacy of Sleep Medicines in Older Adults. Clinical Therapeutics, 38, 2340-2372. https://www.clinicaltherapeutics.com/article/S0149-2918(16)30733-0/fulltext https://doi.org/10.1016/j.clinthera.2016.09.010 
[4] Expert Panel (2012) American Geriatrics Society updated Beers Criteria for Potentially Inappropriate Medication Use in Older Adults. Journal of the American Geriatrics Society, 6, 616-631.

https://onlinelibrary.wiley.com/doi/abs/10.1111/j.1532-5415.2012.03923.x

[5] National Institutes of Health (2014) Despite Risks, Benzodiazepine Use Highest in Older People. National Institutes of Health, Washington DC.

https://www.nih.gov/news-events/news-releases/despite-risks-benzodiazepine-usehighest-older-people

[6] Maust, D.T., Blow, F.C., Wiechers, I.R., Kales, H.C. and Marcus, S.C. (2017) National Trends in Antidepressant, Benzodiazepine, and Other Sedative-Hypnotic Treatment of Older Adults in Psychiatric and Primary Care. Journal of Clinical Psychiatry, 78, e363-e371. https://www.psychiatrist.com/jcp/article/Pages/2017/v78n04/v78n0401.aspx

[7] Maust, D.T., Kales, H.C., Wiechers, I.R., Blow, F.C. and Olfson, M. (2016) No End in Sight: Benzodiazepine Use in Older Adults in the United States. Journal of the American Geriatrics Society, 64, 2546-2553. https://onlinelibrary.wiley.com/doi/abs/10.1111/jgs.14379 https://doi.org/10.1111/jgs.14379

[8] Barnard, E., et al. (1998) International Union of Pharmacology. XV. Subtypes of $\gamma$-Aminobutyric Acid $_{\mathrm{A}}$ Receptors: Classification on the Basis of Subunit Structure and Receptor Function. Pharmacological Reviews, 50, 291-314.

https://www.ncbi.nlm.nih.gov/pmc/articles/PMC2847512/pdf/nihms187538.pdf

[9] Sieghart, W. (1994) Pharmacology of Benzodiazepine Receptors: An Update. Journal of Psychiatry and Neuroscience, 19, 24-29. http://europepmc.org/backend/ptpmcrender.fcgi?accid=PMC1188559\&blobtype=pdf

[10] Costa, E., Guidotti, A., Mao, C.C. and Suria, A. (1975) New Concepts on the Mechanism of Action of Benzodiazepines. Life Sciences, 17, 167-185.

https://www.sciencedirect.com/science/article/abs/pii/0024320575905019 https://doi.org/10.1016/0024-3205(75)90501-9

[11] Haefely, W., Kulcsar, A. and Mohler, H. (1975) Possible Involvement of GABA in the Central Actions of Benzodiazepines. Psychopharmacology Bulletin, 11, 58-59. https://www.ncbi.nlm.nih.gov/pubmed/242199

[12] Haefely, W. (1985) Pharmacology of Benzodiazepine Antagonists. Pharmacopsychiatry, 18, 163-166.

https://www.thieme-connect.com/products/ejournals/pdf/10.1055/s-2007-1017356. pdf https://doi.org/10.1055/s-2007-1017356

[13] Soyka, M. (2017) Treatment of Benzodiazepine Dependence. New England Journal of Medicine, 376, 1147-1157.

https://www.nejm.org/doi/full/10.1056/NEJMra1611832 https://doi.org/10.1056/NEJMra1611832

[14] Zezula, J., Cortes, R., Probst, A. and Palacios, J.M. (1988) Benzodiazepine Receptor Sites in the Human Brain: Autoradiographic Mapping. Neuroscience, 25, 771-795. https://www.sciencedirect.com/science/article/abs/pii/030645228890036X?via\%3Di $\underline{\text { hub }}$

[15] Möhler, H. and Okada, T. (1977) Benzodiazepine Receptor: Demonstration in the Central Nervous System. Science, 198, 849-851.

http://science.sciencemag.org/content/198/4319/849.long https://doi.org/10.1126/science.918669

[16] Squires, R.F. and Braestrup, C. (1977) Benzodiazepine Receptors in Rat Brain. Na- 
ture, 266, 732-734. https://www.nature.com/articles/266732a0

[17] McEnery, M.W., Snowman, A.M., Trifiletti, R.R. and Snyder, S.H. (1992) Isolation of the Mitochondrial Benzodiazepine receptor: Association with the Voltage-Dependent Anion Channel and the Adenine Nucleotide Carrier. Proceedings of the National Academy of Sciences of the United States of America, 89, 3170-3174. https://www.pnas.org/content/89/8/3170 https://doi.org/10.1073/pnas.89.8.3170

[18] Tu, L.N., et al. (2014) Peripheral Benzodiazepine Receptor/Translocator Protein Global Knock-Out Mice Are Viable with No Effects on Steroid Hormone Biosynthesis. Journal of Biological Chemistry, 289, 27444-27454.

http://www.jbc.org/content/289/40/27444 https://doi.org/10.1074/jbc.M114.578286

[19] Endres, C.J., Coughlin, J.M., Gage, K.L., Watkins, C.C., Kassiou, M. and Pomper, M.G. (2012) Radiation Dosimetry and Biodistribution of the TSPO Ligand 11C-DPA-713 in Humans. Journal of Nuclear Medicine, 53, 330-335.

http://jnm.snmjournals.org/content/53/2/330 https://doi.org/10.2967/jnumed.111.094565

[20] Anonymous (2009) Drugs for Insomnia. Medical Letter, 7, 23-26. https://flexiblelearning.auckland.ac.nz/pharmacy735/16/guide-medlet09.pdf

[21] Buffett-Jerrott, S.E. and Stewart, S.H. (2002) Cognitive and Sedative Effects of Benzodiazepine Use. Current Pharmaceutical Design, 8, 45-58.

http://www.eurekaselect.com/64616/article https://doi.org/10.2174/1381612023396654

[22] Lader, M., Tylee, A. and Donoghue, J. (2009) Withdrawing Benzodiazepines in Primary Care. CNS Drugs, 23, 19-34.

https://www.ncbi.nlm.nih.gov/pubmed/19062773

[23] Mura, T., et al. (2013) Chronic Use of Benzodiazepines and Latent Cognitive Decline in the Elderly: Results from the Three-City Study. European Neuropsychopharmacology, 23, 212-223.

https://www.sciencedirect.com/science/article/pii/S0924977X12001393?via\%3Dihub https://doi.org/10.1016/j.euroneuro.2012.05.004

[24] Pariente, A., de Gage, S.B., Moore, N. and Begaud, B. (2016) The Benzodiazepine-Dementia Disorders Link: Current State of Knowledge. CNS Drugs, 30, 1-7. https://link.springer.com/article/10.1007\%2Fs40263-015-0305-4 https://doi.org/10.1007/s40263-015-0305-4

[25] Gustavsen, I., Bramness, J., Skurtveit, S., Engeland, A., Neutel, I. and Morland, J. (2008) Road Traffic Accident Risk Related to Prescriptions of the Hypnotics Zopiclone, Zolpidem, Flunitrazepam, and Nitrazepam. Sleep Medicine, 9, 818-822. https://www.sciencedirect.com/science/article/pii/S1389945707004248?via\%3Dihub https://doi.org/10.1016/j.sleep.2007.11.011

[26] Smink, B.E., Egberts, A.C., Lusthof, K.J., Uges, D.R. and de Gier, J.J. (2010) The Relationship between Benzodiazepine Use and Traffic Accidents: A Systematic Literature Review. CNS Drugs, 24, 639-653.

https://link.springer.com/article/10.2165\%2F11533170-000000000-00000 https://doi.org/10.2165/11533170-000000000-00000

[27] Wagner, A.K., et al. (2004) Benzodiazepine Use and Hip Fractures in the Elderly: Who Is at Greatest Risk? Archives of Internal Medicine, 164, 1567-1572. https://jamanetwork.com/journals/jamainternalmedicine/fullarticle/217249

[28] Koyama, A., Steinman, M., Ensrud, K., Hillier, T.A. and Yaffe, K. (2013) Ten-Year Trajectory of Potentially Inappropriate Medications in Very Old Women: Impor- 
tance of Cognitive Status. Journal of the American Geriatrics Society, 61, 258-263.

https://doi.org/10.1111/jgs.12093

https://onlinelibrary.wiley.com/doi/abs/10.1111/jgs.12093

[29] Pisani, M.A., Murphy, T.E., Araujo, K.L., Slattum, P., Van Ness, P.H. and Inouye, S.K. (2009) Benzodiazepine and Opioid Use and the Duration of Intensive Care Unit Delirium in an Older Population. Critical Care Medicine, 37, 177-183.

https://insights.ovid.com/crossref?an=00003246-200901000-00026 https://doi.org/10.1097/CCM.0b013e318192fcf9

[30] Berryman, S.N., Jennings, J., Ragsdale, S., Lofton, T., Huff, D.C. and Rooker, J.S. (2012) Beers Criteria for Potentially Inappropriate Medication Use in Older Adults. Medical-Surgical Nursing, 21, 129-132.

https://www.ncbi.nlm.nih.gov/pubmed/22866431

[31] FDA (2016) FDA Requires Strong Warnings for Opioid Analgesics, Prescription Opioid Cough Products, and Benzodiazepine Labeling Related to Serious Risks and Death from Combined Use. Food and Drug Administration, Rockville. https://www.fda.gov/NewsEvents/Newsroom/PressAnnouncements/ucm518697.htm

[32] Vukcevic, N.P., Ercegovic, G.V., Segrt, Z., Djordjevic, S. and Stosic, J.J. (2016) Benzodiazepine Poisoning in Elderly. Vojnosanitetski Pregled, 73, 234-238.

http://www.vsp.mod.gov.rs/casopis/106/VSP_1_2017.pdf https://doi.org/10.2298/VSP141208025P

[33] Carrière, I., et al. (2015) Elderly Benzodiazepine Users at Increased Risk of Activity Limitations: Influence of Chronicity, Indications, and Duration of Action-The Three-City Cohort. American Journal of Geriatric Psychiatry, 23, 40-51.

https://www.sciencedirect.com/science/article/pii/S1064748114003169?via\%3Dihub https://doi.org/10.1016/j.jagp.2014.10.006

[34] Borbely, A.A. (1982) A Two Process Model of Sleep Regulation. Human Neurobiology, 1, 195-204. https://www.ncbi.nlm.nih.gov/pubmed/7185792

[35] Krystal, A.D., Benca, R.M. and Kilduff, T.S. (2013) Understanding the Sleep-Wake Cycle: Sleep, Insomnia, and the Orexin System. Journal of Clinical Psychiatry, 74, 3-20. https://www.psychiatrist.com/JCP/article/Pages/2013/v74s01/v74s0101.aspx https://doi.org/10.4088/JCP.13011su1c

[36] Peyron, C., et al. (1998) Neurons Containing Hypocretin (Orexin) Project to Multiple Neuronal Systems. Journal of Neuroscience, 18, 9996-10015.

http://www.jneurosci.org/content/18/23/9996.long https://doi.org/10.1523/JNEUROSCI.18-23-09996.1998

[37] Saper, C.B., Cano, G. and Scammell, T.E. (2005) Homeostatic, Circadian, and Emotional Regulation of Sleep. Journal of Comparative Neurology, 493, 92-98. https://onlinelibrary.wiley.com/doi/abs/10.1002/cne.20770 https://doi.org/10.1002/cne.20770

[38] Zeitzer, J.M., Nishino, S. and Mignot, E. (2006) The Neurobiology of Hypocretins (Orexins), Narcolepsy and Related Therapeutic Interventions. Trends in Pharmacological Sciences, 27, 368-374.

https://www.cell.com/trends/pharmacological-sciences/fulltext/S0165-6147(06)0013 0-1?_returnURL=https\%3A\%2F\%2Flinkinghub.elsevier.com\%2Fretrieve\%2Fpii\%2F S0165614706001301\%3Fshowall\%3Dtrue https://doi.org/10.1016/j.tips.2006.05.006

[39] Morgan, P.T., et al. (2012) Cortical GABA Levels in Primary Insomnia. Sleep, 35, 807-814. https://academic.oup.com/sleep/article/35/6/807/2709385 https://doi.org/10.5665/sleep.1880

[40] Brisbare-Roch, C., et al. (2007) Promotion of Sleep by Targeting the Orexin System 
in Rats, Dogs and Humans. Nature Medicine, 13, 150-155.

https://www.nature.com/articles/nm1544

https://doi.org/10.1038/nm1544

[41] Johnson, B. and Streltzer, J. (2013) Risks Associated with Long-Term Benzodiazepine use. American Family Physician, 88, 224-225.

https://pdfs.semanticscholar.org/94db/522d12555fdcae33baa58e2518a6bdff863e.pdf

[42] Bain, K.T. (2006) Management of Chronic Insomnia in Elderly Persons. American Journal of Geriatric Pharmacotherapy, 4, 168-192.

https://www.sciencedirect.com/science/article/abs/pii/S1543594606000286?via\%3Di hub

https://doi.org/10.1016/j.amjopharm.2006.06.006

[43] Dowell, D., Haegerich, T. and Chou, R. (2016) CDC Guideline for Prescribing Opioids for Chronic Pain United States, 2016. Journal of the Medical Association, 315, 1624-1645. https://jamanetwork.com/journals/jama/fullarticle/2503508

[44] American Geriatrics Society (2015) Updated Beers Criteria for Potentially Inappropriate Medication Use in Older Adults. Journal of the American Geriatrics Society, 63, 2227-4226. https://onlinelibrary.wiley.com/doi/full/10.1111/jgs.13702

[45] Winkelman, J.W. (2015) Insomnia Disorder. New England Journal of Medicine, 373, 1437-1444. https://www.nejm.org/doi/full/10.1056/NEJMcp1412740 https://doi.org/10.1056/NEJMcp1412740

[46] Bramoweth, A.D., et al. (2016) Deconstructing Chronic Low Back Pain in the Older Adult-Step by Step Evidence and Expert-Based Recommendations for Evaluation and Treatment: Part VII: Insomnia. Pain Medicine, 17, 851-863.

https://academic.oup.com/painmedicine/article/17/5/851/1753061 https://doi.org/10.1093/pm/pnw063

[47] Asnis, G.M., Thomas, M. and Henderson, M.A. (2016) Pharmacotherapy Treatment Options for Insomnia: A Primer for Clinicians. International Journal of Molecular Sciences, 17, 50. https://www.mdpi.com/1422-0067/17/1/50

[48] Michelson, D., et al. (2014) Safety and Efficacy of Suvorexant during 1-Year Treatment of Insomnia with Subsequent Abrupt Treatment Discontinuation: A Phase 3 Randomised, Double-Blind, Placebo-Controlled Trial. Lancet Neurology, 13, 461-471.

https://www.thelancet.com/journals/laneur/article/PIIS1474-4422(14)70053-5/fulltext

[49] Keks, N.A., Hope, J. and Keogh, S. (2017) Suvorexant: Scientifically Interesting, Utility Uncertain. Australasian Psychiatry, 25, 622-624.

https:/journals.sagepub.com/doi/abs/10.1177/1039856217734677?journalCode=apya https://doi.org/10.1177/1039856217734677

[50] Keating, G.M. (2016) Tasimelteon: A Review in Non-24-Hour Sleep-Wake Disorder in Totally Blind Individuals. CNS Drugs, 30, 461-468. https://link.springer.com/article/10.1007\%2Fs40263-016-0330-y https://doi.org/10.1007/s40263-016-0330-y

[51] Williams 3rd, W.P., McLin 3rd, D.E., Dressman, M.A. and Neubauer, D.N. (2016) Comparative Review of Approved Melatonin Agonists for the Treatment of Circadian Rhythm Sleep-Wake Disorders. Pharmacotherapy, 36, 1028-1041. https://accpjournals.onlinelibrary.wiley.com/doi/full/10.1002/phar.1822 https://doi.org/10.1002/phar.1822

[52] Reddy, A., Puvvada, S.C., Kommisetti, S., El-Mallakh, R.S. and Lippmann, S. (2015) Suvorexant: Something New for Sleep? Acta Neuropsychiatrica, 27, 53-55. https://www.cambridge.org/core/journals/acta-neuropsychiatrica/article/suvorexant 
-something-new-for-sleep/2D3602EC0A761E88A2C996E6AE27781A

[53] Kuriyama, A. and Tabata, H. (2017) Suvorexant for the Treatment of Primary Insomnia: A Systematic Review and Meta-Analysis. Sleep Medicine Reviews, 35, 1-7. https://www.sciencedirect.com/science/article/pii/S108707921630096X?via\%3Dihub

[54] Neubauer, D.N. (2008) A Review of Ramelteon in the Treatment of Sleep Disorders. Neuropsychiatric Disease and Treatment, 4, 69-79. https://www.ncbi.nlm.nih.gov/pmc/articles/PMC2515902/ https://doi.org/10.2147/NDT.S483

[55] Lockley, S.W., et al. (2015) Tasimelteon for Non-24-Hour Sleep-Wake Disorder in Totally Blind People (SET and RESET): Two Multicentre, Randomised, Double-Masked, Placebo-Controlled Phase 3 Trials. The Lancet, 386, 1754-1764. https://www.thelancet.com/journals/lancet/article/PIIS0140-6736(15)60031-9/fulltext https://doi.org/10.1016/S0140-6736(15)60031-9

[56] McCleery, J., Cohen, D.A. and Sharpley, A.L. (2016) Pharmacotherapies for Sleep Disturbances in Dementia. Cochrane Database of Systematic Reviews, 11, Cd009178.

https://www.cochranelibrary.com/cdsr/doi/10.1002/14651858.CD009178.pub3/full

[57] Schutte-Rodin, S., Broch, L., Buysse, D., Dorsey, C. and Sateia, M. (2008) Clinical Guideline for the Evaluation and Management of Chronic Insomnia in Adults. Journal of Clinical Sleep Medicine, 4, 487-504. https://www.ncbi.nlm.nih.gov/pmc/articles/PMC2576317/pdf/jcsm.4.5.487.pdf

[58] Siegel, S. (2005) Drug Tolerance, Drug Addiction, and Drug Anticipation. Current Directions in Psychological Science, 14, 296-300.

https://journals.sagepub.com/doi/abs/10.1111/j.0963-7214.2005.00384.x https://doi.org/10.1111/j.0963-7214.2005.00384.x

[59] Ramsay, D.S. and Woods, S.C. (1997) Biological Consequences of Drug Administration: Implications for Acute and Chronic Tolerance. Psychological Review, 104, 170-193. https://www.ncbi.nlm.nih.gov/pubmed/9009884

[60] Nitsche, J.F., Schuller, A.G.P., King, M.A., Zengh, M., Pasternak, G.W. and Pintar, J.E. (2002) Genetic Dissociation of Opiate Tolerance and Physical Dependence in $\delta$-Opioid Receptor-1 and Preproenkephalin Knock-Out Mice. Journal of Neuroscience, 22, 10906-2002. http://www.jneurosci.org/content/22/24/10906.long

[61] Baldwin, D.S., Aitchison, K., Bateson, A., Curran, H.V., Davies, S., Leonard, B., Nutt, D.J., Stephens, D.N. and Wilson, S. (2013) Benzodiazepines: Risks and Benefits. A Reconsideration. Journal of Psychopharmacology, 27, 967-971.

https://journals.sagepub.com/doi/abs/10.1177/0269881113503509?journalCode=jopa https://doi.org/10.1177/0269881113503509

[62] Lembke, A., Papac, J. and Humphreys, K. (2018) Our Other Prescription Drug Problem. New England Journal of Medicine, 378, 693-695.

https://www.nejm.org/doi/10.1056/NEJMp1715050 https://doi.org/10.1056/NEJMp1715050

[63] Pétursson, H. (1994) The Benzodiazepine Withdrawal Syndrome. Addiction, 89, 1455-1459.

https://onlinelibrary.wiley.com/doi/abs/10.1111/j.1360-0443.1994.tb03743.x https://doi.org/10.1111/j.1360-0443.1994.tb03743.x

[64] Robinson, T.E. and Berridge, K.C. (1993) The Neural Basis of Drug Craving: An Incentive-Sensitization Theory of Addiction. Brain Research Reviews, 18, 247-291. https://www.sciencedirect.com/science/article/pii/016501739390013P?via\%3Dihub

[65] Ashton, C.H. (2002) Benzodiazepines: How They Work and How to Withdraw. https://www.benzo.org.uk/manual/ 